\title{
The economic implications of using a truly preindustrial climate baseline
}

\author{
Dmitry Yumashev ${ }^{\mathrm{a}, \mathrm{b}}$, Chris Brierley ${ }^{\mathrm{c}}$ \\ ${ }^{a}$ Lancaster University, Pentland Centre for Sustainability in Business, Lancaster, LA1 \\ $4 Y X, U . K$. \\ ${ }^{b}$ University College London, Institute of Sustainable Resources, London, WC1E 6BT, \\ $U . K$. \\ ${ }^{c}$ University College London, Environmental Change Research Centre, Dept. of \\ Geography, London, WC1E 6BT, U.K.
}

\begin{abstract}
The pervasive impacts of climate change can result in scientific decisions having unforeseen societal implications. To demonstrate this, we explore the global and regional economic implications of adopting an earlier preindustrial baseline of 1400-1800 for climate policy targets instead of the commonly used early industrial period of 1850-1900 for which we have observational data. Because of early industrial emissions, the 1400-1800 period was slightly cooler than the 1850-1900 baseline, leaving less headroom before the Paris temperature target is reached and the associated carbon budget is exhausted. While this increases the mitigation costs of cutting emissions, the lower temperature headroom also reduces the expected residual climate impacts, resulting in a mean net economic saving to the world as a whole. The less developed regions in the global South, which have the lowest historic emissions, would see the biggest savings from adopting the earlier preindustrial baseline. Meanwhile, different blocs in the global North are set to experience comparatively small extra costs or no changes at all. Following the IPCC Special Report on the $1.5^{\circ} \mathrm{C}$ world, these findings further highlight the need to consider the equity dimension of climate policy.
\end{abstract}

Keywords: Climate Change, Economic Impacts, Paris Agreement

URL: d.yumashev@lancaster.ac.uk (Dmitry Yumashev) 
2

\section{Introduction}

The IPCC's Special Report on Global Warming of $1.5{ }^{\circ} \mathrm{C}$ stresses the importance of considering social implications in all decisions about climate change (Allen et al., 2018; Masson-Delmotte, 2018). This calls for socioeconomic impact assessments to be used in conjunction with climate science while making policy decisions. As an illustrative example, here we investigate the economic and equity implications of one of the key recommendation made by the IPCC's Special Report: to adopt an earlier preindustrial climate baseline from which the extent of anthopogenic warming is measured. The Paris Agreement (United Nations Framework Convention on Climate Change, 2015) commits the world to keeping global mean temperature to "well-below $2{ }^{\circ} \mathrm{C}$ above preindustrial", while also calling "to pursue efforts to limit the temperature increase even further to $1.5{ }^{\circ} \mathrm{C}$ ". However, a precise definition of this preindustrial reference period (Hawkins et al., 2017) is not explicit in the text of the Agreement (United Nations Framework Convention on Climate Change, 2015), with subsequent studies attempting to clarify the issue (Schurer et al., 2018; Millar et al., 2018). In the wider Earth System context, defining the preindustrial baseline is akin to establishing a start date for the Anthropocene, which has been a subject of considerable academic debate from the geological perspective (Lewis and Maslin, 2015; Waters et al., 2016). An equally important recognition of the social justice perspective has already been introduced into the Anthropocene debate (Ellis et al., 2016).

The early industrial period of 1850-1900 at the beginning of instrumental observations can be considered a fair approximation to the preindustrial climate baseline (Hartmann et al., 2013; Allen et al., 2018). However, there had been anthropogenic emissions before this: industrial coal burning started after the mass adoption of the steam engine in the 1700s (Crutzen, 2002), while land-use changes had already been producing emissions thousands of years ago (Ruddiman, 2013). This means that from a climate policy perspective, an earlier baseline period is desirable, which is why the IPCC (Myhre et al., 2013) adopted the 1750 reference year to account for the bulk of the historic industrial emissions. Any earlier baseline period was likely cooler than the early industrial period of 1850-1900 (Hawkins et al., 2017; Allen et al., 2018), even though the long-term global mean temperatures associated with these two periods are within statistical error of each other (Fig. 1). Approximating the preindustrial baseline with the early instrumental period (Allen et al., 2018) is therefore a valid pragmatic decision (Hawkins et al., 2017). 
The fact that estimating the extent of anthropogenic-driven warming that has already occurred to date requires a reference period (Schurer et al., 2017) has obvious implications for the amount of warming left before the world reaches the temperature targets specified by the Paris Agreement (United Nations Framework Convention on Climate Change, 2015). The choice of the baseline also affects the associated budgets of how much carbon could still be emitted before the Paris targets are missed. This, in turn, alters the projected future mitigation costs and residual climate-driven impacts for a given climate scenario in line with the Paris targets. Here, we quantify the net economic effect of altering the climate reference period by undertaking a cost-benefit analysis under a range of scenarios consistent with the Paris Agreement's targets, using two different approximations of the preindustrial baseline. By sub-dividing this effect at a regional level, we highlight the social justice perspective of the decision to use the earlier climate baseline.

The amount of human-caused warming that had already occurred before the early industrial period (1850-1900) was estimated in a recent study (Schurer et al., 2017) using an ensemble of simulations for the last millennium from multiple climate models, combined with a comprehensive analysis of natural climate drivers during the same period. This made it possible to define an earlier preindustrial baseline, approximated by the average climate between 1400-1800. This earlier reference period, which we refer to as the formal preindustrial baseline, was on average $0.1{ }^{\circ} \mathrm{C}$ cooler compared with the early industrial (1850-1900), leading to a slightly higher temperature anomaly of $1.04 \pm 0.11{ }^{\circ} \mathrm{C}$ for the current climate. In contrast, the estimated present-day anomaly is $0.95 \pm 0.04{ }^{\circ} \mathrm{C}$ when the $1850-1900$ baseline is used Morice et al. (2012) (Fig. 1a).

Similarly, estimates for the amount of historical anthropogenic carbon emissions change with the reference period (le Quéré et al, 2016). The global cumulative emissions in 2015 are estimated at $600 \pm 70 \mathrm{GtC}$ since 1750, and $550 \pm 55 \mathrm{GtC}$ since 1850 (le Quéré et al, 2016). While the difference between the two estimates is relatively small compared to the overall cumulative emissions to date, it is as large as cumulative emissions from some broad economic blocs (Fig. 1). Together with the reduced temperature headroom for meeting the Paris targets when the earlier baseline is used, the historic cumulative emissions associated with the early industrial period limit the remaining carbon budget for the Paris Agreement targets. 


\section{Methods}

\subsection{Selection of a preindustrial baseline}

The climate has varied throughout the last millennium (Hartmann et al., 2013), from the warm Medieval Quiet Period (Bradley et al., 2016) through to the cold Little Ice Age (Matthews and Briffa, 2005). The vast majority of these variations arose from natural forcing, primarily volcanic, although there is discussion of potential impacts of anthropogenic land use and land use change playing a role. Here we follow the approach of Schurer et al. (2017) rather than Hawkins et al. (2017). Hawkins et al. (2017) assess the likely range (i.e. $66 \%$ probability) of warming since their reference period of 1720-1800, and explicitly state that they do not provide a formal uncertainty quantification. Conversely, Schurer et al. (2017) provide a probability distribution for the anthropogenic-driven warming since their reference period of 1400-1800, which is more appropriate for using in the PAGE model. The corresponding probability distributions for the global mean surface temperature (GMST) anomaly associated with the climatology around 2015 are plotted in Figure 1 alongside the estimates for the historic carbon emissions from the IPCC's Special Report on Global Warming of $1.5{ }^{\circ} \mathrm{C}$ (Allen et al., 2018).

\subsection{Experimental Setup}

Converting the high ambition of the Paris Agreement into the probabilistic input parameters for the PAGE model requires certain assumptions to be made. We choose emissions scenarios that require extra mitigation relative to RCP2.6 and result in a $66 \%$ confidence of not exceeding $1.5^{\circ} \mathrm{C}$ and $2{ }^{\circ} \mathrm{C}$ in 2100 , depending on which preindustrial baseline is chosen. We also consider several scenarios between these two targets. Although not as ambitious as the $1.5{ }^{\circ} \mathrm{C}$ target, the $2{ }^{\circ} \mathrm{C}$ scenario still requires considerably deeper mitigation than the current national pledges as part of the Paris Agreement (Rogelj et al., 2016). It remains a desirable target given the reported increase in global emissions for a second year in a row following a stagnation between 2014-2016 (Figueres et al., 2018), which implies that many countries are expected to miss out on their current pledges before the first ratcheting-up exercise takes place in 2020.

All costs presented in the manuscript are based on taking the equityweighted (Anthoff et al., 2009) net present value (NPV) between 2015-2300 with the pure time preference (PTP) discount rate of $0.1-2 \%$, and using 
purchasing power parity (PPP) GDP projections following the SSP1 "Sustainability" scenario (Riahi et al., 2017), which is consistent with ambitious mitigation targets. The US\$ tn figures in the manuscript are the Monte-Carlo mean NPVs of the change in the total economic effect of climate change under a specified scenario, or the mean NPVs of the statistical differences between the economic effects corresponding to the two preindustrial baselines.

The GMST anomaly and cumulative carbon emissions in 2015 are assumed to be $100 \%$ correlated with one another within a given preindustrial baseline. This is equivalent to the assumption that the present-day GMST anomaly is fully driven by the historic carbon emissions, regardless of which baseline we use. All the other uncertain parameters of PAGE20 (around 150, see the technical description of the PAGE-ICE model (Yumashev et al., 2019)) are assumed to be uncorrelated. This is a common practice in the probabilistic IAMs like PAGE, which is justified by the underlying complexities of both the climatic and socio-economic systems.

We assume that the probability distributions describing both the climatological 2015 GMST anomaly and cumulative carbon are 50\% correlated between the earlier (1400-1800) and conventional (1850-1900) baselines. This implies that if the actual 2015 temperature and cumulative carbon turn out to be on the higher end of the uncertainty range for the conventional baseline, they are more likely going to be on the equivalent higher end of the uncertainty range for the earlier baseline, even though there is no perfect correlation between the two. The latter would have been an overly strong assumption which we believe is not justified in view of the existing uncertainties.

We meet the discrete GMST targets in the range from $1.5{ }^{\circ} \mathrm{C}$ to $2{ }^{\circ} \mathrm{C}$ $\left(0.1{ }^{\circ} \mathrm{C}\right.$ increment) by adding an extra compounding abatement rate to the RCP2.6 scenario, depending on the choice of the preindustrial baseline, and running a statistical optimisation algorithm iteratively several times. As a result, each target within the range is hit with high accuracy regardless of the baseline choice. When comparing between the two baselines for any given target within the $1.5{ }^{\circ} \mathrm{C}-2{ }^{\circ}$ range, the relative error in the 66th percentile values of the GMST projections for 2100 is below $0.05 \%$ when using 100,000 Monte-Carlo runs. The high accuracy makes it possible to analyse the difference between the economic effects associated with the two baselines.

Figure 2 shows the full statistical distribution of the difference between the total economic effect of climate change for the early industrial (1850- 
1900) and formal preindustrial (1400-1800) baselines. The was obtained using 100,000 Monte-Carlo runs of the PAGE20 model, assuming the $2{ }^{\circ}$ scenario and the level effects in terms of climate-driven changes to economic growth (see below). While most of the distribution lies in the positive territory, resulting in the mean $\$ 13.3$ tn saving from adopting the formal baseline, around $20 \%$ of the values are negative. They correspond to a small number of cases when switching to the earlier baseline leads to an extra cost globally. This situation occurs when the 2015 temperature anomaly and cumulative carbon emissions for the earlier (1400-1800) baseline appear lower than those for the conventional (1850-1900) baseline. Represented by the lower-end tail in Figure 1, this overlap is due to the higher standard deviations describing the 2015 conditions using the earlier and therefore more uncertain baseline.

\subsection{Updates to the PAGE model}

PAGE20 is the latest version of the PAGE model allowing one to use a preindustrial baseline prior to the 19th Century, in addition to the conventional 1850-1900 baseline. The model now uses 2015 as its start year, in which the GMST anomaly is adjusted to represent a climatological value by means of decadal smoothing (Morice et al., 2012). The GMST anomaly and cumulative carbon emissions in 2015 for each preindustrial baseline follow normal distributions with the parameters described in the main text. The model runs out to 2300 to capture slow processes such as sea level rise from degrading ice sheets and ocean carbon sink.

PAGE20 also includes all the updates to climate science and economics from the latest literature that are part of another recent version of the PAGE model called PAGE-ICE (Yumashev et al., 2019). One of the main updates in PAGE-ICE is the new economic impact function based on the latest macro-econometric analysis of correlations between historic annual temperature shocks and economic growth in multiple countries by Burke et al. (2015), projected onto the 8 major regions of the PAGE model using population-weighted temperatures. Because of the high uncertainty surrounding medium-term and long-term impacts on economic growth caused by annual temperature-related stresses, we adapted the impact function by Burke et al. (2015) to fit with the single year consumption-only approach for climate impacts traditionally used in PAGE. The latter is know an as the level effects of temperature changes on economy, and provides an incremental adjustment to the modelling framework of PAGE. The consumption-only 
approach also implies that our impact estimates are likely to be on a conservative side (Dietz and Stern, 2015).

To test the sensitivity of the results to the level effects assumption for climate impacts, we conducted the partial growth effects experiment. This experiment assumes that, in addition to the level-type climate impacts occurring in a given region in each year according to the Burke curve, the same region also faces a half of its level impacts carried from the previous year, a quarter of the impacts from two years before, and so on. As a result, the total impact in a given year is represented by a geometric series, which is a special case of the growth effects model for climate damages.

The climate science updates in PAGE-ICE include: adjusted equilibrium climate sensitivity (ECS) based on IPCC AR5; revised CO2 cycle in line with the latest multi-model assessment of the atmospheric $\mathrm{CO} 2$ response function (Joos et al., 2013); amplification factors for the regional temperatures based on the complete CMIP5 pool of climate models; and, fat-tailed distribution for the sea level rise (SLR) time lag (at the lower values end) to account for the possible acceleration in the discharge from the West Antarctica and Greenland ice sheets (Nauels et al., 2017).

The economics updates in PAGE-ICE, in addition to the Burke et al. (2015) impact function, include: considerably reduced saturation limit for the impacts, in line with the effect of the Great Depression in the US; modified uncertainty range for the "business as usual" emissions scenario (used as a reference point for calculating the abatement costs), covering the range roughly between RCP6.0 and a pathway exceeding RCP8.5 (Christensen et al., 2018); revised present-day marginal abatement cost (MAC) curves, technological learning rate (CO2 only) and autonomous technological change based on energy efficiency improvements (Aldy et al., 2016; Rubin et al., 2015; ETP, 2012); significantly downscaled discontinuity sector, which now accounts only for socio-economic tipping points such as pandemics, mass migration and wars.

In the results presented here, we do not consider planned adaptation apart from that aimed at reducing impacts of sea level rise, which is know to be highly cost-effective (Hinkel et al., 2014) and is an order of magnitude lower than all the other costs involved. The focus is therefore on the interplay between temperature-driven climate impacts and mitigation spending. Although planned adaptation to rising temperatures is excluded, the new economic impact function in PAGE20, being based on the comprehensive analysis of historic temperature-economy correlations by Burke et al. (2015), 
is expected to include autonomous adaptation.

\section{Results}

After the influential Stern review of the economics of climate change was published over a decade ago (Her Majestys Treasury, 2006), the PAGE integrated assessment model has been widely used to guide climate policy decisions. PAGE combines a simplified model of the Earth system with 8 economic blocs to determine the costs of a specified set of mitigation and adaptation policies and the associated climate-induced impacts across four broad categories: sea level rise, economic losses (or benefits) driven by rising temperatures (Burke et al., 2015), non-economic impacts associated with ecosystems and human health, and climatic and societal tipping points (Hope, 2013). The sum of the climate impacts, mitigation costs and adaptation costs, referred to as the total economic effect of climate change, is one of the main policy-relevant indicators estimated by the PAGE model under a specified set of scenarios for the global socio-economic development and the associated greenhouse gas emissions. PAGE is inherently probabilistic and uses Monte-Carlo sampling to explore the climatic and economic implications of uncertainty in the multiple parameters defining the model (Hope, 2015).

The version of the PAGE model used in this study, referred to as PAGE20, includes the two preindustrial baselines introduced above, and has several critical updates to reflect recent insights in both climate science and economics (Methods). In particular, the rates of technological progress have been updated to ensure the mitigation costs of cutting GHG emissions account for the recent reductions in the prices of renewables (Aldy et al., 2016; Rubin et al., 2015), while also taking into account the likely business-asusual emissions trajectories (Christensen et al., 2018). Most importantly, the temperature-driven component of the climate impacts now follows the recent macro-econometric analysis of historic impacts of country-level temperature shocks on economic growth (Burke et al., 2015; Yumashev et al., 2019). However, while using the core results for the climate-induced pressures on economic growth in each year, we additionally assume that the resulting GDP losses are fully recovered in the end of each year and the economy returns to its original trajectory. Termed as level effects, this approach is known to give a more conservative estimate for climate impacts compared to growth effects, when the lost GDP is never recovered (Burke et al., 2015; Piontek et al., 2018). Current data suggests that both types of economic responses 
to rising temperatures are possible depending on a country's socio-economic and climatic conditions (Burke et al., 2015; Newell et al., 2018; Piontek et al., 2018). Like in previous model versions, level effects is the default approach in PAGE. The sensitivity of the results to this choice is demonstrated by also considering partial growth effects, where $50 \%$ of the total GDP impacts (across the four major categories in PAGE) in each year propagate to the next year.

The PAGE20 Monte-Carlo mean estimate of the global total economic effect of the scenario with a likely $(66 \%)$ chance of staying within $2{ }^{\circ} \mathrm{C}$ of the early industrial (1850-1900) baseline in 2100 is around US $\$ 594 \mathrm{tn}^{1}$ for the level effects (Fig. 3a), with roughly $60 \%$ of the price tag coming from the negative impacts of climate change, also known as damages. If partial growth effects were to occur this increases to US\$ 969 tn (Fig. 3b), of which $75 \%$ is due to damages. Raising the ambition to the likely chance of staying within $1.5{ }^{\circ} \mathrm{C}$ of the early industrial baseline in 2100 increases the mean of the total economic effect of climate change from US\$594 th to US\$ $652 \mathrm{tn}$ for the level effects (Fig. 3a), and decreases it from US\$ 969 tn to US\$ 918 tn for the partial growth effects (Fig. 3b). Critically, whether there is a higher total cost associated with lower temperature target is conditional on the persistence of the economic effect of climate impacts (Piontek et al., 2018; Newell et al., 2018). Even when the partial growth effects are considered, the $1.5{ }^{\circ} \mathrm{C}$ scenario becomes more economically attractive (Burke et al., 2018) when the 1400-1800 baseline is used.

How would these results change if we were to use the formal 1400-1800 baseline for setting the temperature targets instead? Selecting the cooler, earlier baseline means that more warming and more carbon emissions had already occurred by 2015 (Fig. 1), leaving less headroom until we reach the temperature caps of the Paris Agreement (United Nations Framework Convention on Climate Change, 2015). In other words, the earlier baseline makes a given target more stringent, which implies more money must be spent on mitigation to cap the total cumulative carbon emissions at the required lower amount. However, the closer temperature target also reduces the residual climate impacts. It turns out that this reduction in the impacts

\footnotetext{
${ }^{1}$ Net present value (NPV) between 2015 and 2300, with pure-time preference (PTP) discount rate varying from 0.1 to $2 \%$, and regional equity-weighting based on marginal utility of consumption.
} 
is bigger than the increase in the mitigation costs when the earlier baseline is adopted. As a result, for any specified target in the range between $1.5^{\circ} \mathrm{C}$ and $2{ }^{\circ} \mathrm{C}$, PAGE20 simulates that using the earlier $1400-1800$ baseline provides a net reduction in the total economic effect of climate change globally relative to the 1850-1900 baseline (Fig. 3). Assuming level effects, the mean reduction is US\$ 13.3 th for the $2{ }^{\circ} \mathrm{C}$ scenario and US $\$ 6.9$ tn for the $1.5{ }^{\circ} \mathrm{C}$ scenario (Fig. 3a). These reductions become larger in the partial growth effects setting: US\$ 30.1 tn for the $2{ }^{\circ} \mathrm{C}$ scenario and US $\$ 22.0$ tn for the $1.5{ }^{\circ} \mathrm{C}$ scenario (Fig 3b, see Methods for discussion of confidence). For context, the estimated PPP GDP of the South Asian bloc of countries, which includes India, was around US $\$ 9.5 \mathrm{tn}$ in 2015; this is exceeded only by US $\$ 19.4$ tn for the United States, and US $\$ 23.3$ tn for the East Asian bloc, which includes China.

Variations in the total cost of climate change depending on whether the 1400-1800 or the 1850-1900 baseline is used differ between regions. We illustrate this in Fig. 4 using the $2{ }^{\circ} \mathrm{C}$ scenario and the level effects assumption. The largest savings are in South Asia (SA, including India) and Africa and Middle East (Af\&ME) - regions that are set to experience the highest losses from climate change due to their already high temperatures, large populations and comparatively low consumption levels (Hope, 2013). The latter implies that a unit loss in consumption has a proportionately higher impact on the people compared to a richer region like the EU, which is quantified by means of equity weighing (Anthoff et al., 2009). In the EU, switching to the earlier baseline is set to increase the economic effect of climate change (Fig. 4), primarily through limiting the initial climate benefits in the colder countries (Burke et al., 2015). However, this extra cost in the EU is an order of magnitude lower than the savings in the SA and Af\&ME regions. The US, in comparison, shows an almost equal probability of either a saving or an extra cost to occur when switching to the earlier preindustrial baseline. A large part of this stems from the fact that the US is near the optimum on the Burke et al. (2015) curve describing temperature-driven impacts on the economy in the PAGE model (Yumashev et al., 2019). Overall, the magnitude of the variations in the economic effect in the US is similar to that in the $\mathrm{EU}$, and is an order of magnitude lower than the net saving from using the earlier baseline for the $2{ }^{\circ} \mathrm{C}$ scenario in the SA and Af\&ME regions. 


\section{Discussion and Implications}

The recent IPCC's Special Report on Global Warming of $1.5^{\circ} \mathrm{C}$ discusses the interplay between equity, sustainable development and poverty eradication (Allen et al., 2018). Inequality between nations (or economic blocs in the PAGE model) is created in part because of their relative contributions to carbon dioxide concentrations (as indicated by their historic cumulative emissions, Fig. 1), which were used to fuel past economic growth. Additionally climate impacts are not evenly distributed and fall disproportionately in the Tropics (Hoegh-Guldberg et al., 2018). The result is magnified by the higher vulnerability to losses in consumption in poorer countries in the global South quantified by the equity weighting (Anthoff et al., 2009; Hope, 2013). On the other hand, some of the colder countries in the global North are set to experience limited initial benefits from the warmer climate (Burke et al., 2015), which could be reduced marginally by adopting the earlier baseline and therefore making both the $1.5{ }^{\circ} \mathrm{C}$ and $2{ }^{\circ} \mathrm{C}$ targets from the Paris Agreement more stringent. Having less headroom to meet a specified target, of course, requires deeper cuts of fossil-fuel emissions and increases mitigation as a result. The highest mitigation costs are expected to occur in South Asia, and Africa \& Middle East, where emissions are set to grow considerably over the course of the 21st century while these nations are undergoing rapid industrialisation. As with the climate impacts, the effect is exacerbated by the equity weighting.

When the changes both in the climate impacts and mitigation costs associated with adopting the earlier baseline under both the $1.5{ }^{\circ} \mathrm{C}$ and $2{ }^{\circ} \mathrm{C}$ scenarios are added together, the result is a considerable economic savings to the global South, and a mixed picture in the global North: different blocs in the North are set to experience comparatively small additional costs or no changes at all. Figure 5 summarises the results of adopting the new baseline across multiple targets between $1.5^{\circ} \mathrm{C}$ and $2{ }^{\circ} \mathrm{C}$, showing the mean savings or extra costs for each region against its respective historic carbon emissions. Both Fig. 4 \& 5 assume the level effects; using partial growth effects would exacerbate the differences (Fig. 3). Those regions that would see the most benefit from a more stringent interpretation of the Paris Agreement are the ones that have contributed the least to the emissions so far.

Starting the Anthropocene around 1600CE has already been proposed from a social justice perspective (Davis and Todd, 2017), which fits with the suggested definition of the preindustrial climate baseline as the average cli- 
mate between 1400-1800CE that we have adopted here (Schurer et al., 2017). When setting their working definition of the preindustrial baseline, the IPCC Special Report explains the need to balance the greater knowledge about the climate of the 19th Century with the greater uncertainty in our estimates of the historic carbon emissions before 1850 (Allen et al., 2018). In the section immediately prior to this explanation, the report states the necessity to consider issues of equity in climate-related decisions. By contributing to what may seem to be a largely academic debate about the definition of the preindustrial baseline, our aim is to further highlight the need to consider the equity dimension of climate policy.

The main consequence of adopting an earlier preindustrial baseline is having less headroom until the Paris Agreement's temperature targets are reached. Our finding that equity is best achieved by adopting this baseline is therefore an extension of the IPCC Special Report's headline statement (Masson-Delmotte, 2018) that "the avoided climate change impacts ... would be greater if global warming were limited ...". The consequences of the choice of the preindustrial baseline, of course, pales compared to the inequalities that would be introduced by nations not fulfilling their commitments under the Paris Agreement.

\section{Acknowledgements}

Prof. Paul Ekins (UCL) generously provided funding that supported part of this work. Andrew Schurer, Natalie Wennyk and Maryam Ilyas helped to determine the preindustrial distribution shown in Fig. 1. We would also like to thank those who commented on draft of this work, including Olivier Dessens, Chris Hope, Mark Maslin and David Thornalley.

\section{Author contributions statement}

C.B. and D.Y. conceived this research, D.Y. conducted the experiment. Both authors analysed the results and wrote the manuscript.

\section{Additional information}

The authors declare no competing interests. 


\section{References}

le Quéré et al, C., 2016. Global carbon budget. Earth Syst. Sci. Data 8, 605-649.

Aldy, J., Pizer, W., Tavoni, M., Reis, L.A., Akimoto, K., Blanford, G., Carraro, C., Clarke, L.E., Edmonds, J., Iyer, G.C., et al., 2016. Economic tools to promote transparency and comparability in the paris agreement. Nature Climate Change 6, 1000.

Allen, M., Dube, O.P., Solecki, W., Aragón-Durand, F., Cramer, W., Humphreys, S., Kainuma, M., Kala, J., Mahowald, N., Mulugetta, Y., Perez, R., Wairiu, M., Zickfeld, K., Dasgupta, P., Eakin, H., Hayward, B., Liverman, D., Millar, R., Raga, G., Ribes, A., Richardson, M., Rojas, M., Séférian, R., Seneviratne, S., Smith, C., Steffen, W., Thorne, P., 2018. Framing and context, in: Global Warming of $1.5 \mathrm{oC}$ : an IPCC special report. Cambridge University Press.

Anthoff, D., Hepburn, C., Tol, R.S., 2009. Equity weighting and the marginal damage costs of climate change. Ecological Economics 68, 836-849.

Bradley, R.S., Wanner, H., Diaz, H.F., 2016. The medieval quiet period. The Holocene 26, 990-993.

Burke, M., Davis, W.M., Diffenbaugh, N.S., 2018. Large potential reduction in economic damages under un mitigation targets. Nature 557, 549.

Burke, M., Hsiang, S.M., Miguel, E., 2015. Global non-linear effect of temperature on economic production. Nature 527, 235.

Christensen, P., Gillingham, K., Nordhaus, W., 2018. Uncertainty in forecasts of long-run economic growth. Proceedings of the National Academy of Sciences 115, 5409-5414.

Crutzen, P.J., 2002. Geology of mankind. Nature 415, 23.

Davis, H., Todd, Z., 2017. On the importance of a date, or decolonizing the anthropocene. ACME: An International E-Journal for Critical Geographies 16. 
Dietz, S., Stern, N., 2015. Endogenous growth, convexity of damage and climate risk: how nordhaus' framework supports deep cuts in carbon emissions. The Economic Journal 125, 574-620.

Ellis, E., Maslin, M., Boivin, N., Bauer, A., 2016. Involve social scientists in defining the anthropocene. Nature News 540, 192.

ETP, I., 2012. Energy technology perspectives 2012: Pathways to a clean energy system.

Figueres, C., Le Quéré, C., Mahindra, A., Bäte, O., Whiteman, G., Peters, G., Guan, D., 2018. Emissions are still rising: ramp up the cuts.

Gütschow, J., Jeffery, M.L., Gieseke, R., Gebel, R., Stevens, D., Krapp, M., Rocha, M., 2016. The primap-hist national historical emissions time series. Earth System Science Data 8, 571-603.

Hartmann, D.L., Tank, A.M.K., Rusticucci, M., Alexander, L.V., Brönnimann, S., Charabi, Y.A.R., Dentener, F.J., Dlugokencky, E.J., Easterling, D.R., Kaplan, A., et al., 2013. Observations: atmosphere and surface, in: Climate Change 2013 the Physical Science Basis: Working Group I Contribution to the Fifth Assessment Report of the Intergovernmental Panel on Climate Change. Cambridge University Press.

Hawkins, E., Ortega, P., Suckling, E., Schurer, A., Hegerl, G., Jones, P., Joshi, M., Osborn, T.J., Masson-Delmotte, V., Mignot, J., et al., 2017. Estimating changes in global temperature since the preindustrial period. Bulletin of the American Meteorological Society 98, 1841-1856.

Her Majestys Treasury, 2006. Stern review on the economics of climate change. London: HM Treasury 30.

Hinkel, J., Lincke, D., Vafeidis, A.T., Perrette, M., Nicholls, R.J., Tol, R.S., Marzeion, B., Fettweis, X., Ionescu, C., Levermann, A., 2014. Coastal flood damage and adaptation costs under 21st century sea-level rise. Proceedings of the National Academy of Sciences 111, 3292-3297.

Hoegh-Guldberg, O., Jacob, D., Taylor, M., Bindi, M., Brown, S., Camilloni, I., Diedhiou, A., Djalante, R., Ebi, K., Engelbrecht, F., Guiot, J., Hijioka, Y., Mehrotra, S., Payne, A., Seneviratne, S.I., Thomas, A., Warren, R., Zhou, G., 2018. Impacts of 1.5 oc global warming on natural and human 
systems, in: Global Warming of 1.5 oC: an IPCC special report. Cambridge University Press.

Hope, C., 2013. Critical issues for the calculation of the social cost of co 2: why the estimates from page09 are higher than those from page2002. Climatic Change 117, 531-543.

Hope, C., 2015. The $\$ 10$ trillion value of better information about the transient climate response. Phil. Trans. R. Soc. A 373, 20140429.

Joos, F., Roth, R., Fuglestvedt, J., Peters, G., Enting, I., Bloh, W.v., Brovkin, V., Burke, E., Eby, M., Edwards, N., et al., 2013. Carbon dioxide and climate impulse response functions for the computation of greenhouse gas metrics: a multi-model analysis. Atmospheric Chemistry and Physics 13, 2793-2825.

Lewis, S.L., Maslin, M.A., 2015. Defining the anthropocene. Nature 519, 171.

Masson-Delmotte, V. (Ed.), 2018. Global Warming of 1.5C: An IPCC Special Report on the Impacts of Global Warming of 1.5C Above Preindustrial Levels and Related Global Greenhouse Gas Emission Pathways, in the Context of Strengthening the Global Response to the Threat of Climate Change, Sustainable Development, and Efforts to Eradicate Poverty. World Meteorological Organization.

Matthews, J.A., Briffa, K.R., 2005. The little ice age: re-evaluation of an evolving concept. Geografiska Annaler: Series A, Physical Geography 87, $17-36$.

Millar, R.J., Fuglestvedt, J.S., Friedlingstein, P., Rogelj, J., Grubb, M.J., Matthews, H.D., Skeie, R.B., Forster, P.M., Frame, D.J., Allen, M.R., 2018. Reply to 'interpretations of the paris climate target'. Nature Geoscience 11, 222-222.

Morice, C.P., Kennedy, J.J., Rayner, N.A., Jones, P.D., 2012. Quantifying uncertainties in global and regional temperature change using an ensemble of observational estimates: The hadcrut4 data set. Journal of Geophysical Research: Atmospheres 117. 
Myhre, G., Shindell, D., Bron, F.M., Collins, W., Fuglestvedt, J., Huang, J., Koch, D., Lamarque, J.F., Lee, D., Mendoza, B., Nakajima, T., Robock, A., Stephens, G., Takemura, T., Zhang, H., 2013. Cambridge University Press.

Nauels, A., Rogelj, J., Schleussner, C.F., Meinshausen, M., Mengel, M., 2017. Linking sea level rise and socioeconomic indicators under the shared socioeconomic pathways. Environmental Research Letters 12, 114002.

Newell, R., Prest, B., Sexton, S., 2018. The GDP-Temperature Relationship: Implications for Climate Change Damages. Technical Report. RFF Working Paper. Available at: http://www. rff. org/research/publications .

Piontek, F., Kalkuhl, M., Kriegler, E., Schultes, A., Leimbach, M., Edenhofer, O., Bauer, N., 2018. Economic growth effects of alternative climate change impact channels in economic modeling. Environmental and Resource Economics , 1-29.

Riahi, K., Van Vuuren, D.P., Kriegler, E., Edmonds, J., Oneill, B.C., Fujimori, S., Bauer, N., Calvin, K., Dellink, R., Fricko, O., et al., 2017. The shared socioeconomic pathways and their energy, land use, and greenhouse gas emissions implications: an overview. Global Environmental Change 42, 153-168.

Rogelj, J., Den Elzen, M., Höhne, N., Fransen, T., Fekete, H., Winkler, H., Schaeffer, R., Sha, F., Riahi, K., Meinshausen, M., 2016. Paris agreement climate proposals need a boost to keep warming well below 2 c. Nature 534,631 .

Rubin, E.S., Azevedo, I.M., Jaramillo, P., Yeh, S., 2015. A review of learning rates for electricity supply technologies. Energy Policy 86, 198-218.

Ruddiman, W.F., 2013. The anthropocene. Annual Review of Earth and Planetary Sciences 41, 45-68.

Schurer, A., Cowtan, K., Hawkins, E., Mann, M., Scott, V., Tett, S., 2018. Interpretations of the paris climate target. Nature Geoscience 11, 220.

Schurer, A.P., Mann, M.E., Hawkins, E., Tett, S.F., Hegerl, G.C., 2017. Importance of the pre-industrial baseline for likelihood of exceeding paris goals. Nature climate change 7, 563 . 
United Nations Framework Convention on Climate Change, 2015. Adoption of the Paris Agreement FCCC/CP/2015/10/Add.1.

Waters, C.N., Zalasiewicz, J., Summerhayes, C., Barnosky, A.D., Poirier, C., Gałuszka, A., Cearreta, A., Edgeworth, M., Ellis, E.C., Ellis, M., et al., 2016. The anthropocene is functionally and stratigraphically distinct from the holocene. Science 351, aad2622.

Yumashev, D., Hope, C., Schaefer, K., Riemann-Campe, K., Iglesias-Suarez, F., Jafarov, E., Burke, E.J., Young, P.J., Elshorbany, Y., Whiteman, G., 2019. Climate policy implications of nonlinear decline of arctic land permafrost and other cryosphere elements. Nature Communications 10, 1900. 

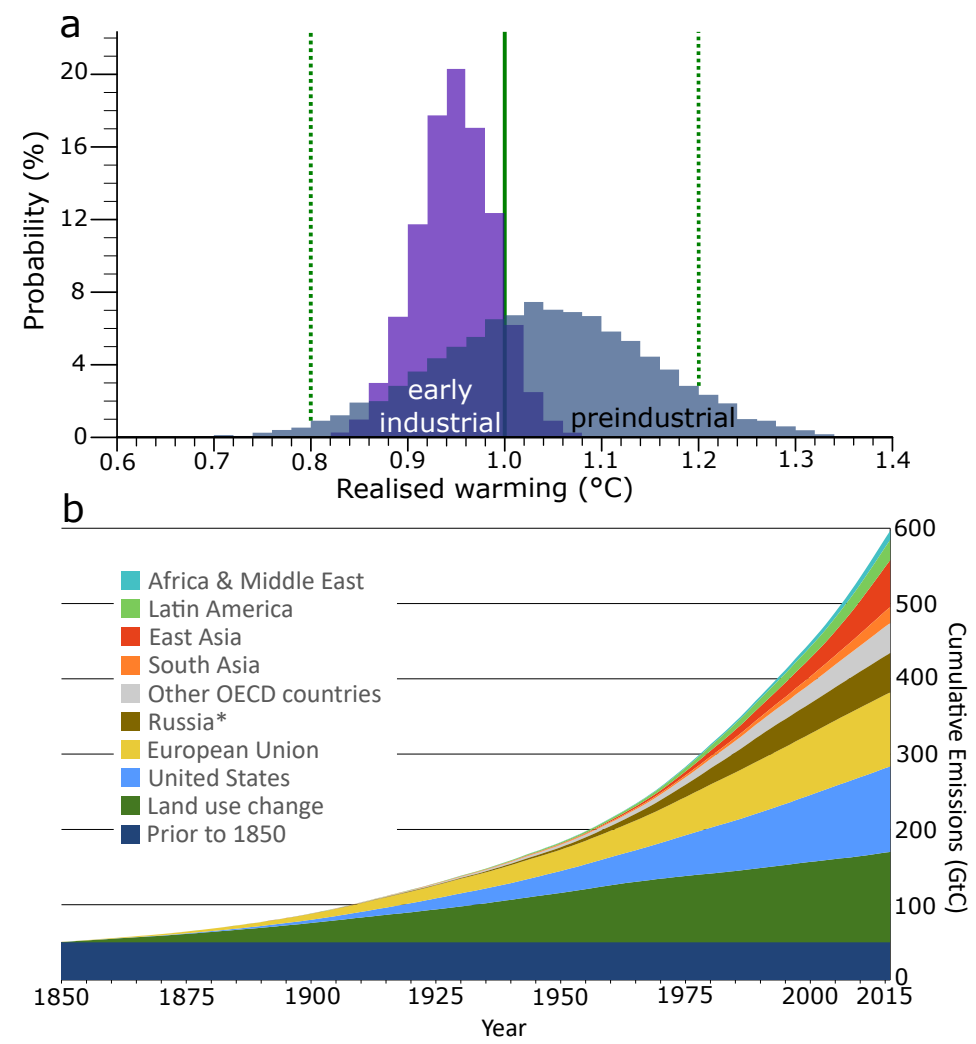

Figure 1: The warming and cumulative carbon emissions from fossil fuels, land use and land use change estimated with respect to the early industrial (1850-1900) and formal preindustrial (1400-1800) climate baselines. (a) Global mean surface temperature (GMST) anomaly of the 2015 climatological period relative to the two baselines; the green lines show the mean estimate and the likely range from the IPCC Special Report (Allen et al., 2018). (b) Cumulative carbon emissions by major economic blocs between 1850-2015 (Gütschow et al., 2016), along with the additional emissions prior to 1850 (le Quéré et al, 2016). *used as an abbreviation for 'Russia and other former Soviet Union states'. 


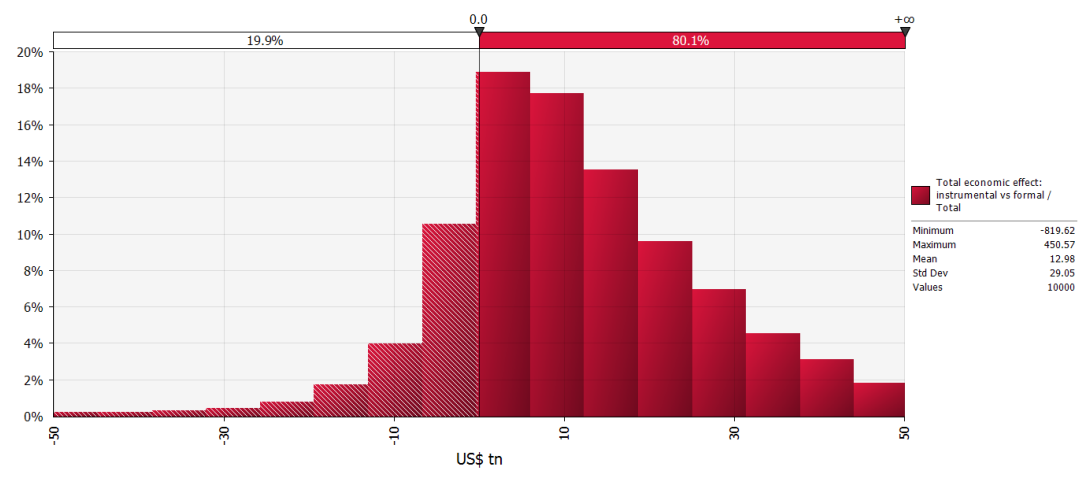

Figure 2: Histogram showing the statistical difference between the total economic effects of climate change for the early industrial (1850-1900) and formal preindustrial (1400-1800) baselines (US\$ tn, NPV until 2300, PTP discount rate, equity weighting). $2{ }^{\circ} \mathrm{C}$ scenario, level effects. Source: 200,000 runs of PAGE20.
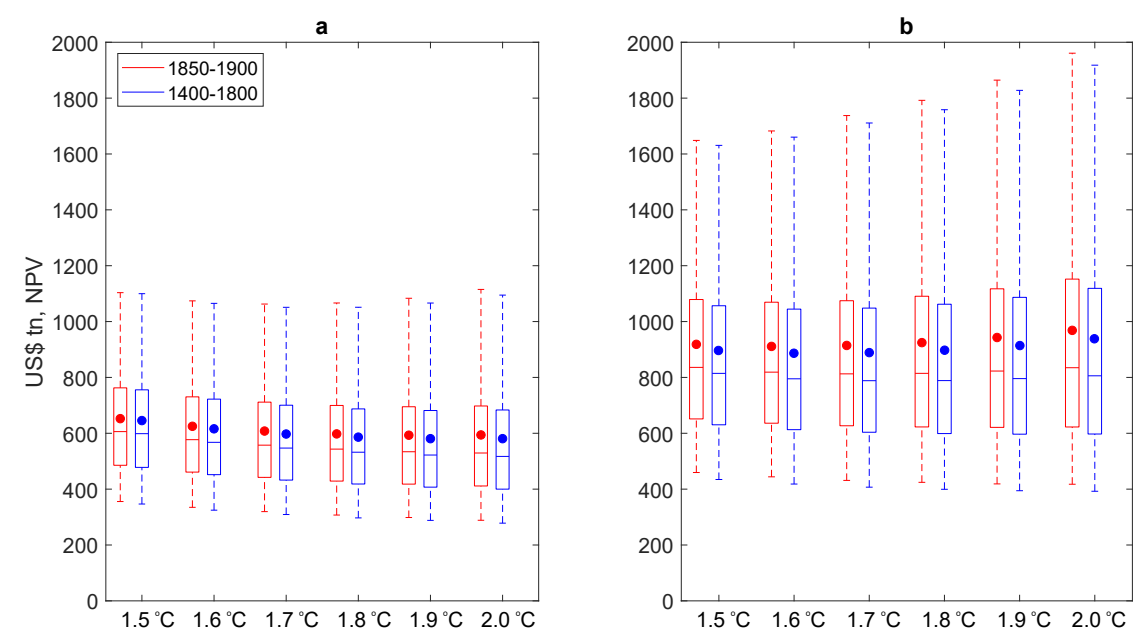

Figure 3: Total economic effect of climate change for the early industrial (1850-1900, red) and formal preindustrial (1400-1800, blue) baselines across multiple temperature targets in 2100 (66\% confidence), assuming (a) level effects and (b) partial growth effects. Dots: means; boxes: 25th-75th percentiles (with medians); whiskers: 5th-95th percentiles. Source: 200,000 runs of PAGE20. 


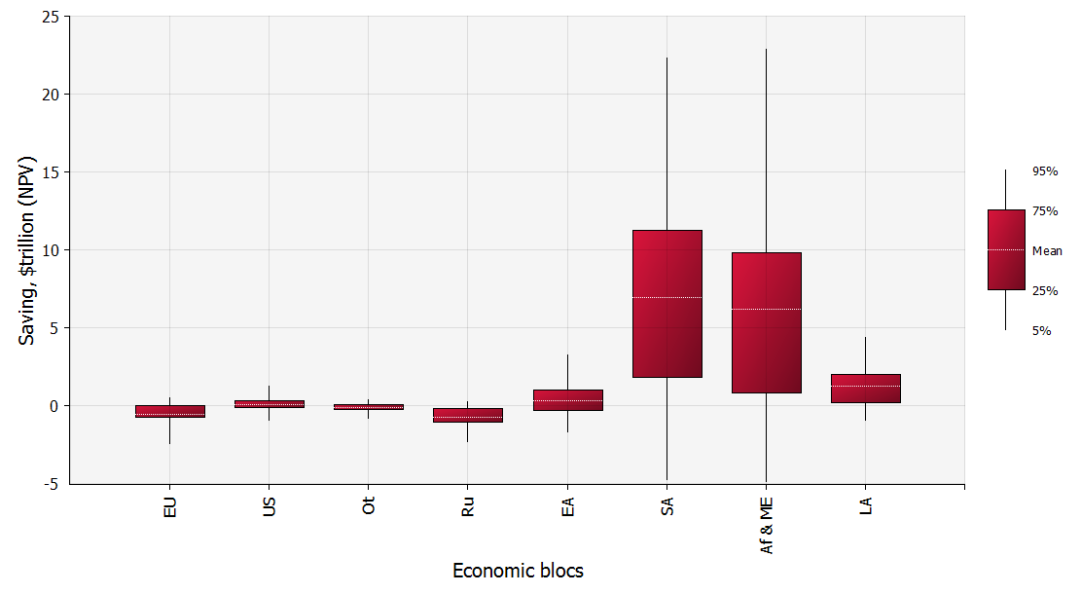

Figure 4: Regional breakdown of the difference between the total economic effects of climate change for the early industrial (1850-1900) and formal preindustrial (1400-1800) baselines for the $2{ }^{\circ} \mathrm{C}$ scenario and the level effects assumption. Regional codes: $\mathrm{EU}=$ European Union, US $=$ United States of America, OT $=$ Other OECD countries, $\mathrm{Ru}=$ Russia \& other former Soviet Union countries, EA = East Asia inc. China, SA = South Asia inc. India, Af\&ME = Africa \& Middle East, LA=Latin America. Source: 200,000 runs of PAGE20. 


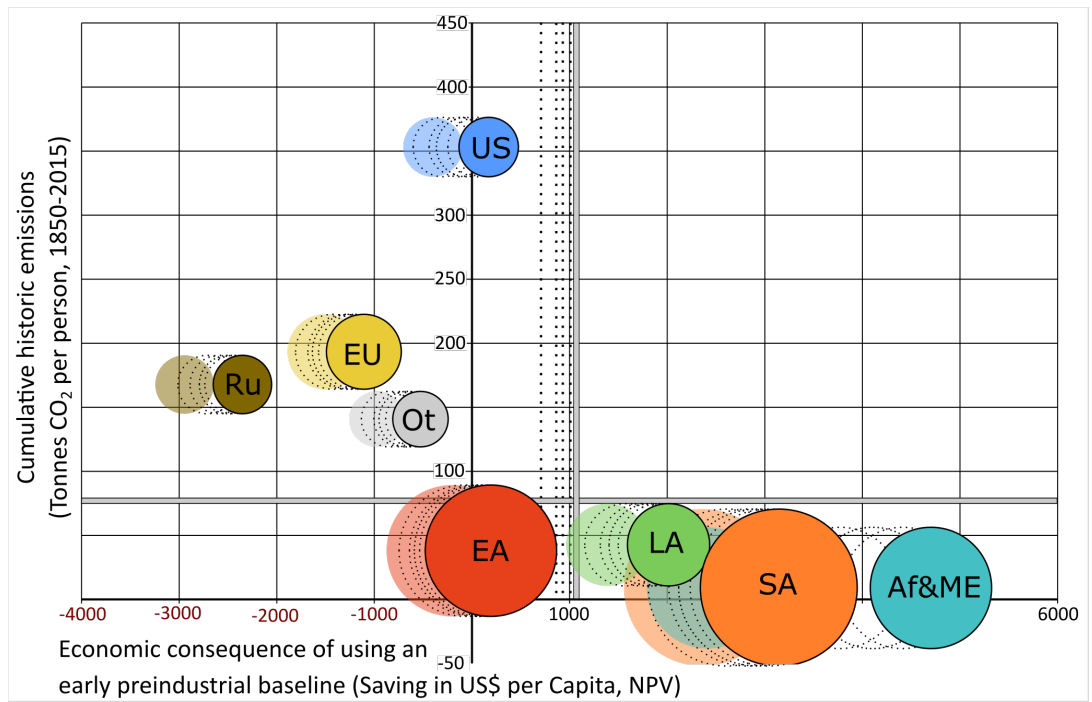

Figure 5: The net economic consequences of adopting an earlier preindustrial baseline in each economic bloc (region) relative to its historic cumulative carbon emissions, based on the level effects assumption for climate impacts. Horizontal axis: per-capita mean savings (benefits) from adopting the earlier baseline (source: 200,000 runs of PAGE20). Vertical axis: per-capita cumulative emissions from 1959-2016 (the full extent of historic country-level emissions data is given in the Global Carbon Budget (le Quéré et al, 2016)). Filled bubbles: $2{ }^{\circ} \mathrm{C}$ scenario; shaded bubbles: $1.5{ }^{\circ} \mathrm{C}$ scenario; dashed bubble contours: scenarios in between the two. Bubble size: relative population of each region in 2015. Vertical lines: net global per-capita benefits for the $2{ }^{\circ} \mathrm{C}$ scenario (solid black), $1.5{ }^{\circ} \mathrm{C}$ scenario (solid grey) and scenarios in between the two (dashed). The regions are defined in Fig. 4. 